\title{
Prevention of Prostate Cancer in Transgenic Adenocarcinoma of the Mouse Prostate Mice by Yellow Passion Fruit Extract and Antiproliferative Effects of Its Bioactive Compound Piceatannol
}

\author{
Larissa Akemi Kido ${ }^{1,2}$, Eun-Ryeong Hahm ${ }^{3}$, Su-Hyeong $\mathrm{Kim}^{3}$, Andressa Mara Baseggio', Valeria Helena Alves Cagnon ${ }^{2}$, \\ Shivendra V. Singh ${ }^{3,4, *}$, Mário Roberto Maróstica Jr. ${ }^{1, *}$ \\ ${ }^{1}$ Department of Food and Nutrition, Faculty of Food Engineering, University of Campinas, ${ }^{2}$ Department of Structural and \\ Functional Biology, Institute of Biology, University of Campinas, Campinas, Brazil, ${ }^{3}$ Department of Pharmacology and \\ Chemical Biology and ${ }^{4}$ UPMC Hillman Cancer Center, University of Pittsburgh School of Medicine, Pittsburgh, PA, USA
}

\begin{abstract}
Piceatannol (PIC), a polyphenol presents in many vegetables and fruits including yellow passion fruit extract (PFE; Passiflora edulis), has anti-cancer activity, but its molecular targets are still poorly understood. The aims of this study were to investigate the molecular mechanistic actions of PIC in prostate cancer cell lines and to test if the extract from PFE rich in PIC can affect the growth of prostate cancer cells in the Transgenic Adenocarcinoma of the Mouse Prostate (TRAMP) model. The PC-3, 22Rv1, LNCaP, and VCaP prostate cancer cells were exposed to PIC (10-40 $\mu \mathrm{M})$, and cell viability, lactate measurement, Western blot, and flow cytometric analyses were performed. For an in vivo experiments, eight-week-old TRAMP mice ( $n=10$ per group each) received an aqueous extract of PFE containing $20 \mathrm{mg}$ of PIC/kg or water (control group) by gavage for 4 or 10 weeks for further analyses. PIC treatment concentration- and time-dependently reduced viability of all cell lines tested. 22Rv1 and LNCaP cells treated with PIC did not exhibit any significant alteration in the intracellular accumulation of lactate. PIC treatment caused $\mathrm{G}_{0} / \mathrm{G}_{1}$ phase cell cycle arrest and induction of apoptosis in both LNCaP and 22Rv1 cells. PIC-treated cells exhibited altered protein levels of p53, p21, cyclin D1, and cyclin-dependent kinase 4 (cdk4). The short and long-term PFE treatments also affected p21, cyclin D1 and cdk4 and delayed disease progression in TRAMP, with a decreased incidence of preneoplastic lesions. In conclusion, PIC apparently does not alter glucose metabolism in prostate cancer cells, while cell cycle arrest and p53 modulation are likely important in anti-cancer effects of $\mathrm{PIC}$ alone or as a food matrix byproduct in prostate cancer cells, especially those with an androgen-dependent phenotype.
\end{abstract}

Key Words Prostate cancer, Bioactive compounds, Passion fruit, Piceatannol, Transgenic adenocarcinoma of the mouse prostate

\section{INTRODUCTION}

Prostate cancer (PCa) is the most common type of cancer among men in the United States and is considered a global public health problem [1]. In 2020, 191,930 new cases of $\mathrm{PCa}$ and 33,330 deaths are estimated from this malignancy in the United States [1]. It is known that nutrition plays an important role in the initiation, promotion, and progression of several cancer types, including PCa [2-5]. It is also clear that along with substances that may increase the risk of cancer development, the human diets also contain chemopreventive or anticarcinogenic components. Therefore, possibility of cancer prevention by non-toxic agents, preferably from dietary sources, has emerged as a strategy for disease control [6]. Micronutrients present in edible plants are considered the most desirable class of chemopreventive agents, and epidemiological studies suggest that consumption of fresh fruits and vegetables may decrease the incidence and the mortality of

Received March 26, 2020, Revised May 19, 2020, Accepted May 20, 2020

Correspondence to Mário Roberto Maróstica Jr., E-mail: mmarosti@unicamp.br, https://orcid.org/0000-0001-8877-3160

Check for updates Shivendra V. Singh, E-mail: singhs@upmc.edu, https://orcid.org/0000-0002-3733-144X

*These authors contributed equally to this work as co-correspondence authors. 
PCa and other types of malignancies [7-11]. Among the different chemopreventive classes of phytochemicals, the polyphenolic antioxidants are quite abundant in food and vegetable beverages consumed by the human population [10,12-14].

Passiflora edulis, popularly known as passion fruit, is a species widely cultivated in Brazil and used in processed juice industry [15]. The largest passion fruit producers are concentrated in South America, especially Brazil, Colombia, Peru, and Ecuador [16]. The peels, seeds, leaves, and flowers of the passion fruit present characteristics of technological and biological interest [17], and studies have shown that different polyphenols have diverse biological effects, such as anti-anxiety [18,19], anti-inflammatory [20], and anti-oxidative properties $[15,21]$. Other studies have shown that passion fruit seeds contain large amounts of piceatannol (PIC) [22], and PIC dimers, such as scirpusin B [23], which are characterized by their intense antioxidant activity.

PIC, like resveratrol, has anti-cancer properties [24,25]. These include cell-cycle arresting, pro-apoptotic, anti-inflammatory, anti-angiogenic, and anti-metastatic activities [26]. In PCa, PIC was reported to reduce invasive and migrative capacity of DU145 cells, which was associated with inhibition of expression of metalloproteinase-9 (MMP-9), VEGF, and urokinase type plasminogen activator [27]. This study also showed that PIC blocked STAT3 signaling through inhibition of interleukin-6 (IL-6) secretion, possibly by influencing MMP9 and VEGF reduction [27]. Similarly, PIC has an inhibitory effect on IL-6/STAT3 signaling that further accentuates intra-tumoral apoptosis via the activation of the death-receptor and mitochondria-dependent pathways [28]. Furthermore, PIC treatment was able to inhibit the lung metastasis of different cancerous prostate cells [27].

In the present study, we explored the molecular mechanistic action of PIC in PCa cell lines, and to evaluate its potential for PCa chemoprevention. In addition, this study was intended to investigate the effects of yellow passion fruit extract (PFE), which is already reported as a PIC source, on the progression of early neoplastic lesions in the Transgenic Adenocarcinoma of the Mouse Prostate (TRAMP) mice.

\section{MATERIALS AND METHODS}

\section{Ethics statement}

Animal use for this study was approved by the Committee of Ethics in Animal Research (protocol 4801-1/2018) and was in agreement with the Ethical Principles for Animal Research (COBEA, Rio de Janeiro, Brazil).

\section{Chemical and biochemicals}

PIC (purity 99.8\%) was purchased from Selleck Chemicals (Houston, TX, USA) and dissolved in dimethyl sulfoxide (DMSO) to make a $100 \mathrm{mM}$ stock solution that was aliquoted and stored at $-80^{\circ} \mathrm{C}$ until use. FBS, PBS, antibiotic mixture, and F-12K Nutrient Mixture were purchased from Life Tech-
nologies-Thermo Fisher Scientific (Waltham, MA, USA). Dulbecco's Modified Eagles Medium (DMEM) was purchased from American Type Culture Collection (Manassas, VA, USA). RPMI-1640 was purchased from Corning (Corning, NY, USA). A kit for colorimetric measurement of lactate was purchased from BioVision (Milpitas, CA, USA). Oligofectamine ${ }^{\mathrm{TM}}$ from Life Technologies-Thermo Fisher Scientific was used for transfection. p53-targeted small interfering RNA (siRNA) was obtained from Santa Cruz Biotechnology (Dallas, TX, USA) and the control siRNA was from Qiagen (Valencia, CA, USA). Anti- $\beta$-actin and anti-p53 antibodies were from Sigma-Aldrich (St. Louis, MO, USA). Antibodies against cyclin-dependent kinase 4 (cdk4) and p21 were from BD Biosciences (San Jose, CA, USA). Anti-cyclin D1 antibody was from Santa Cruz Biotechnology and anti-glyceraldehyde 3-phosphate dehydrogenase (anti-GAPDH) antibody was from GeneTex (Irvine, CA, USA). Anti- $\beta$-actin (sc-81178) antibody used for animal samples was from Santa Cruz Biotechnology.

\section{Cell lines}

PC-3, LNCaP, VCaP, and 22Rv1 cells were obtained from the ATCC and authenticated by us in 2017 . The PC-3 cell line was maintained in $\mathrm{F}-12 \mathrm{~K}$ medium supplemented with $10 \%$ FBS, $1 \%$ antibiotic mixture, whereas $\mathrm{LNCaP}$ and $22 \mathrm{Rv} 1$ cell lines were maintained in RPMI medium supplemented with $10 \%$ of FBS, $1 \%$ of antibiotic mixture, $10 \mathrm{mM}$ HEPES, $1 \mathrm{mM}$ sodium pyruvate, and $2,500 \mathrm{mg} / \mathrm{L}$ glucose. The VCaP cells were maintained in DMEM supplemented with $20 \%$ FBS and $1 \%$ antibiotic mixture.

\section{Cell viability assay}

Monolayer cultures of PC-3, VCaP, LNCaP, and 22Rv1 cells were maintained in a humidified atmosphere of $95 \%$ air and $5 \% \mathrm{CO}_{2}$ at $37^{\circ} \mathrm{C}$. The trypan blue dye exclusion assay was performed to assess the effect of PIC on viability of $\mathrm{PCa}$ cells. The cells (PC-3, $5 \times 10^{4}$; VCaP, $7.5 \times 10^{4}$; LNCaP, $5 \times 10^{4}$; $22 \mathrm{Rv} 1,1 \times 10^{5}$ ) were plated in 12-well plates in triplicate and allowed to attach overnight. The medium was replaced with fresh complete medium containing different concentrations of PIC $(10 \mu \mathrm{mol} / \mathrm{L}, 20 \mu \mathrm{mol} / \mathrm{L}$, or $40 \mu \mathrm{mol} / \mathrm{L})$, and the plates were incubated for 24,48 , or 72 hours at $37^{\circ} \mathrm{C}$. Stock solution of the PIC was prepared in DMSO, and an equal volume of DMSO (final concentration $0.1 \%$ ) was added to the control wells. At the end of the incubation, the cells were collected and suspended in $75 \mu \mathrm{L}$ PBS. The cells were then mixed with $75 \mu \mathrm{L} 0.2 \%$ trypan blue solution, and live (unstained) cells were counted under an inverted microscope.

\section{Quantification of intracellular lactate levels}

The intracellular lactate level was determined in LNCaP and 22Rv1 cells using a commercially available kit (BioVision, Milpitas, CA, USA) and by following the suppliers' instructions. 


\section{Cell cycle analysis}

The effect of PIC on cell cycle distribution was determined by flow cytometry after staining the cells with propidium iodide. The PCa cell lines $\left(22 \mathrm{Rv} 1,5 \times 10^{5}\right.$; LNCaP, $\left.3.5 \times 10^{5}\right)$ were seeded in 60-mm dishes in triplicate and allowed to attach overnight. The medium was replaced with fresh complete medium containing DMSO or the desired concentrations of PIC, and the plates were incubated for 8,16 , or 24 hours at $37^{\circ} \mathrm{C}$. Adherent cells were collected, washed with PBS, fixed with $70 \%$ ethanol, and kept at least for 24 hours at $-20^{\circ} \mathrm{C}$. The cells were then treated with $80 \mu \mathrm{g} / \mathrm{mL}$ RNase A and 50 $\mu \mathrm{g} / \mathrm{mL}$ propidium iodide for 45 minutes. Then, the stained cells were analyzed using a BD Accuri C6 flow cytometer.

\section{Western blot analysis}

$\operatorname{LNCaP}\left(3.5 \times 10^{5}\right)$ and $22 \operatorname{Rv} 1\left(5 \times 10^{5}\right)$ cells were seeded in 60-mm dishes, allowed to attach overnight, and then treated with DMSO or desired concentrations of PIC for 8,16 , or 24 hours. Cell lysates were prepared in ice-cold lysis buffer containing $50 \mathrm{mmol} / \mathrm{L}$ Tris- $\mathrm{HCl}(\mathrm{pH} 8.0), 1 \%$ Triton $\mathrm{X}-100,0.1 \%$ sodium dodecyl sulfate, $150 \mathrm{mmol} / \mathrm{L} \mathrm{NaCl}$, and protease and phosphatase inhibitor cocktail mixture.

The lysates were separated by centrifugation at 14,000 rpm for 15 minutes, and protein content in supernatant fraction was quantified by the Bradford method. Lysates containing 20-30 $\mu \mathrm{g}$ protein were subjected to SDS PAGE, and the proteins were transferred onto polyvinylidene fluoride membrane. After blocking with non-fat dry milk (5\%) in TBS containing Tween-20, membranes were probed with a desired primary antibody followed by the appropriate peroxidase-conjugated secondary antibody. The immunoreactive bands were visualized by enhanced chemiluminescence detection system according to the manufacturer's instructions. To ensure equal protein loading, each membrane was stripped and re-probed with anti- $\beta$-actin or anti-GAPDH antibody. The software UN-SCAN-IT5.1 (Silk Scientific, Orem, UT, USA) was used to quantify the protein level changes relative to control.

\section{RNA interference of p53}

LNCaP cells $\left(2.0 \times 10^{5}\right)$ and 22Rv1 $\left(7.5 \times 10^{5}\right)$ cells were seeded in 6-well plates and 60-mm dishes, respectively, and transfected at $50 \%$ confluency with a control (non-specific) siRNA or p53-targeted siRNA. After 24 hours of transfection, the cells were treated with DMSO (control) or PIC (40 $\mu \mathrm{mol} /$ L) for 24 hours. The cells were then collected and processed for Western blotting and cell cycle analysis by flow cytometry.

\section{Animal model and treatments with PFE}

A total of forty male TRAMP mice (C57BL/6-Tg [TRAMP] $8247 \mathrm{Ng} / \mathrm{JX}$ FVB/JUnib) were purchased from Multidisciplinary Center for Biological Investigation in Laboratory Animal Science at the University of Campinas. Mice in this study received water and solid diet ad libitum (Nuvilab; Quimtia S/A, Colombo, Brazil). The animals were divided into two control groups (CT) with different ages that represent the end of the treatments: 12-week-old TRAMP mice $(\mathrm{n}=$ $10)$ and 18 -week-old TRAMP mice $(n=10)$. These animals ( $n=10$ per group) received water orally by gavage during four (from 8- to 12-week-old) (CT-4 wk) and ten weeks (from 8- to 18-week-old) (CT-10 wk), three times per week. The treated groups ( $n=10$ per group) received an aqueous extract of yellow passion fruit ( $P$. edulis) bagasse (seeds more remaining pulp) orally by gavage $(20 \mathrm{mg} / \mathrm{kg} / \mathrm{d}$ of PIC present in the aqueous PFE) during 4 (PFE-4 wk) or 10 weeks (PFE$10 \mathrm{wk}$ ), three times per week. The inclusion of two different periods of treatment is justified by the cancer progression of the TRAMP model. From 8 to 12 weeks, we simulate a preventive treatment because the predominant lesions are noncancerous during this period, whereas preneoplastic and neoplastic lesions are more common after 12 weeks of treatment.

The literature reports that passion fruit seed present higher amounts of phenolic compounds and the main component is the PIC $[22,23,29,30]$. The yellow passion fruit $(P$. edulis Sims.) used in this study was obtained from a rural producer "Sítio do Bello" (23 27' 45" S, 45 42' 30" W, Paraibuna, Sao Paulo State, Brazil). We performed an extraction of yellow passion fruit bagasse using the protocol of Viganó et al. [30] that is more efficient for the recovery of phenolic acids. The PIC content in the extract was quantified representing $20 \%$ of phenolic compounds (data not shown). Thus, the dose was calculated based on the amount of PIC present in the PFE, and we established a dose of $20 \mathrm{mg} / \mathrm{kg} / \mathrm{d}$ of PIC present in the aqueous PFE adapted from Song et al. [31]. At the end of the treatment, the animals were anesthetized with $2 \%$ xylazine hydrochloride $(5 \mathrm{mg} / \mathrm{kg}$ ) and $10 \%$ of ketamine hydrochloride $(60 \mathrm{mg} / \mathrm{kg})$, and euthanized. The ventral prostate was collected and processed for microscopy and Western blot analysis.

\section{Analysis of PCa in TRAMP mice}

The prostate samples $(n=5)$ for each experimental group were fixed in Bouin solution for 24 hours, rinsed in $70 \%$ ethanol, dehydrated in increasing concentrations of ethanol, incubated in xylene, and embedded in Histosec ${ }^{\circledR}$ pastilles (Merck, Darmstadt, Germany). The blocks were cut into $5 \mu \mathrm{m}$ thick sections and the slides were stained with H\&E. For morphological analyses, ten random, non-overlapping images at $\times 400$ magnification were captured following the counting system described previously [32]. The tissue classification followed the descriptions already defined in previous studies [33]. The lesions were classified into low-grade prostatic intraepithelial neoplasia (LGPIN), high-grade prostatic intraepithelial neoplasia (HGPIN), and well-differentiated adenocarcinoma (WDA). The percentage of each pathological feature was determined for each experimental group. The ventral prostate samples $(n=5)$ from all experimental groups were used for Western blotting. 


\section{Statistical analysis}

Statistical analysis was performed using GraphPad Prism (ver. 7.02). One-way analysis of variance followed by Dunnett's or Bonferroni's test was carried out for statistical comparisons with the level of significance set at $5 \%$. For TRAMP analysis unpaired $t$-test was used with the same level of significance. The results were expressed as the mean \pm SD.

\section{RESULTS}

\section{PIC affected viability of PCa cell lines with different genetic backgrounds}

The PIC treatment reduced viability of all PCa cell lines tested. In order to determine the effective concentration able to alter cell viability, we tested different concentrations of PIC $(10,20$, and $40 \mu \mathrm{mol} / \mathrm{L})$ (Fig. 1). It is important to mention that PC-3 cells are androgen-independent and phosphatase and tensin homolog (PTEN) and p53 null, whereas VCaP is an androgen-responsive wild-type PTEN and mutant p53 cell line. LNCaP is an androgen-responsive cell line that expresses mutant androgen receptor (T877A), mutant PTEN, and wild-type $\mathrm{p} 53$. On the other hand, 22Rv1 expresses wildtype PTEN, mutant p53, mutant androgen receptor and its splice variants. As seen in Figure 1, PIC treatment caused a statistically significant decrease in the number of viable cells in all cell lines in a concentration- and time-dependent manners. The PC-3 cell viability was significantly altered by PIC after 24, 48, and 72 hours of treatment (20 and $40 \mu \mathrm{mol} /$ $\mathrm{L})$, and the cell viability was significantly inhibited at a lower concentration $(10 \mu \mathrm{mol} / \mathrm{L})$ with increased exposure time (Fig. 1A). Regarding VCaP cells, a greater effect was seen following 24 hours of exposure to PIC at all concentrations (Fig. 1B). PIC treatment also showed concentration- and time-dependent inhibitory effects on the viability of LNCaP cells (Fig. 1C). $22 R v 1$ cells were the least sensitive to growth inhibition by PIC (Fig. 1D) at the 24 hour when compared to the other cells lines.

\section{The intracellular lactate level was not affected by PIC}

In order to access the effect of PIC on PCa cell metabolism, we determined the intracellular levels of lactate. PIC treatment declined an intracellular lactate level in LNCaP cells, but not in 22Rv1 cells (Figure S1). Although there was a significant decrease in lactate levels in LNCaP cells, from the biological point of view, this difference may not substantial to alter the glucose metabolism. We also investigated if PIC could alter free fatty acids levels in VCaP cells, but the results did not show any alteration (data not shown). Considering these results about cellular metabolism. We explored alternative mechanism(s) of PIC action.

\section{PIC treatment caused cell cycle arrest and induced cell death in LNCaP and 22Rv1 cells} In the present study, we chose LNCaP and 22Rv1 cells to determine whether the growth inhibitory effect of $\mathrm{PIC}$ in $\mathrm{PCa}$ cells was due to its ability to cause cell cycle arrest, as seen in other reports in the literature [34,35]. PIC exposure was responsible for the induction of cell cycle arrest in both cell lines as seen in the Figure 2 and 3. In LNCaP cells, there was an increase in the proportion of $G_{0} / G_{1}$ phase cells after 16 hours and 24 hours of exposure to PIC at 20 and $40 \mu \mathrm{mol} / \mathrm{L}$ and 40 $\mu \mathrm{mol} / \mathrm{L}$ concentrations, respectively (Fig. 2). In 22Rv1 cells, the cell cycle arrest was evident even after 8 hours of treatment (Fig. 3). Moreover, PIC treatment led to $\mathrm{G}_{0} / \mathrm{G}_{1}$ arrest in $22 \mathrm{Rv} 1$ cells after 24 hours of treatment at the $40 \mu \mathrm{mol} / \mathrm{L}$ concentration (Fig. 3). A similar effect was detected in 22Rv1 cells in the sub- $G_{0} / G_{1}$ phase (Fig. 3). It is known that sub- $G_{0} /$ $\mathrm{G}_{1}$ peaks is indicative of appearance of apoptotic cells, as well as part of necrotic cells. Significant increases of cells in sub- $G_{0} / G_{1}$ phase account for the capability of PIC to inhibit viability and to induce apoptosis of both $\mathrm{PCa}$ cell lines examined.

In order to elucidate the mechanisms linked to the response of PCa cells to PIC, we measured the levels of p53, p21, cyclin D1, and cdk4 proteins by Western blot analysis. As shown in Figure 4, PIC treatment caused an increase in the p53 protein level, and this effect was more pronounced after 8 hours of treatment in LNCaP and 16 hours of treatment in 22Rv1 cells (Fig. 4). The level of p21 was also increased after PIC treatment with a progressive fold change increase in both cell lines mostly at the $40 \mu \mathrm{mol} / \mathrm{L}$ concentration (Fig. 4). Cyclin D1 and cdk4 are key molecules that play an important role in progression of the cell cycle. After PIC treatment, there was an apparent decrease in the cyclin D1 and cdk4 protein levels in both cell lines (Fig. 4).

\section{Cell cycle arrest in LNCaP cells by PIC was regulated by $\mathrm{p} 53$}

The Western blotting results showed that PIC modulated the p53 level in both cell lines. Considering that LNCaP is wildtype for p53 and 22Rv1 contains mutant p53, we intended to investigate the role for this tumor suppressor in cell cycle arrest by PIC. To achieve this, we performed silencing of p53 expression by siRNA (Fig. 5). We first determined the optimal conditions for transfection of p53 siRNA and then the silencing was confirmed by Western blotting in both cell lines (Fig. 5A and 5C). As seen in Figure 5B, PIC treatment caused $G_{0} / G_{1}$ phase arrest in control siRNA transfected $L N$ CaP cells that was partly attenuated by knockdown of p53. The induction of p53 protein resulting from PIC exposure was also partly abrogated by RNA interference of p53 (Fig. 5A). The percentage of sub- $\mathrm{G}_{0} / \mathrm{G}_{1}$ population after $\mathrm{PIC}$ treatment was slightly higher in p53 knockdown cells than that in control siRNA transfected cells (Fig. 5B). The results were different in $22 R v 1$ cells. First, the $G_{0} / G_{1}$ phase arrest was not seen in 

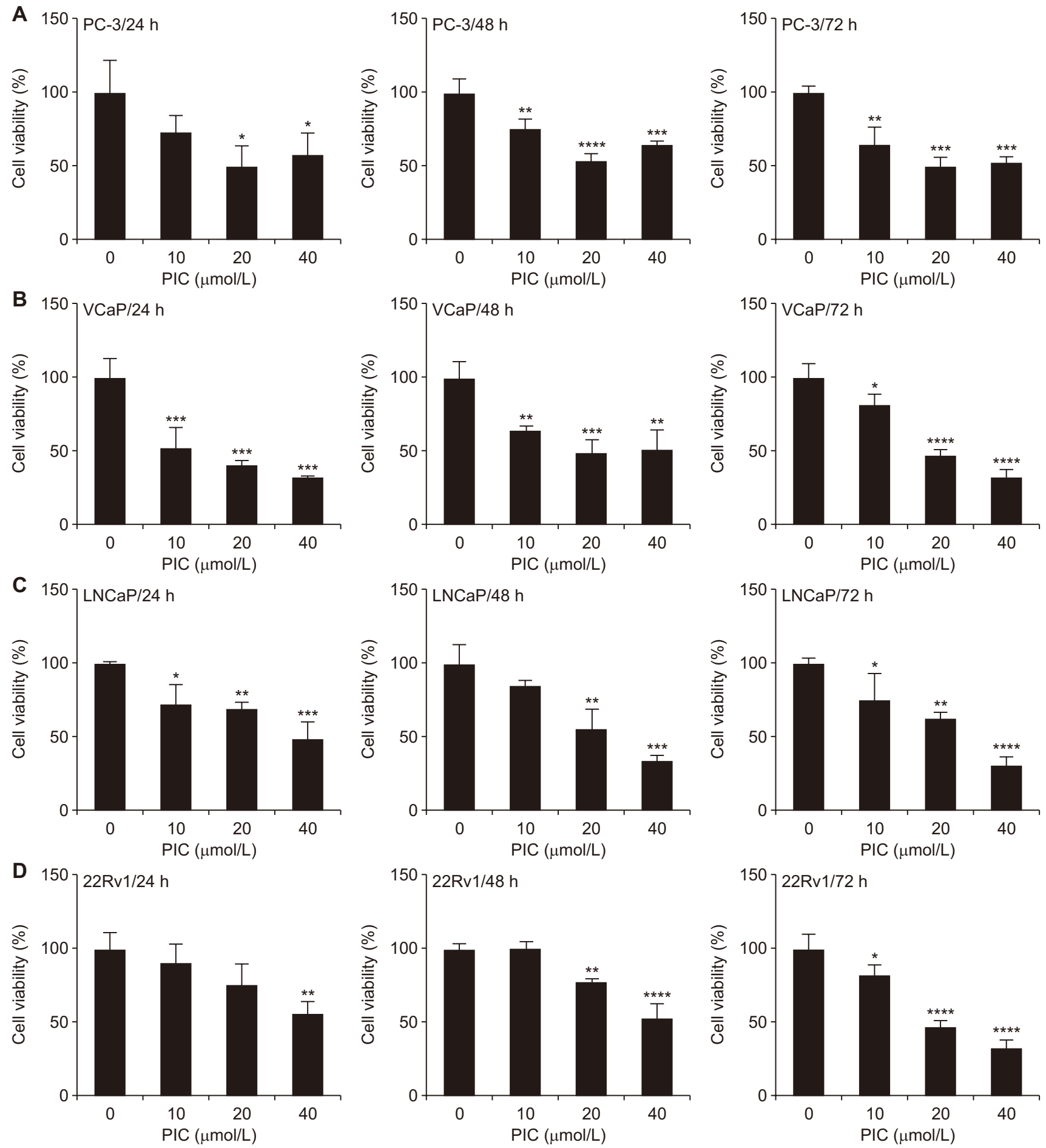

Figure 1. Dose response effect of piceatannol (PIC) on cell viability of PC-3, VCaP, LNCaP, and 22Rv1 cells. Viability of (A) PC-3, (B) VCaP, (C) LNCaP, and (D) 22Rv1 prostate cancer cells after treatment with dimethyl sulfoxide (DMSO) or different concentrations of PIC for 24, 48, and 72 hours was determined by the trypan blue dye exclusion assay as described in Materials and Methods. The results are expressed as mean \pm SD $(n=3)$. Significantly different $\left({ }^{\star} P<0.05 ;{ }^{* \star} P<0.01 ;{ }^{* \star *} P<0.001 ;{ }^{* \star \star *} P<0.0001\right)$ compared with corresponding DMSO-treated control by one-way analysis of variance followed by Dunnnett's test. The experiments were repeated twice with consistent results. Representative data from one such experiment is shown. 
Kido et al.
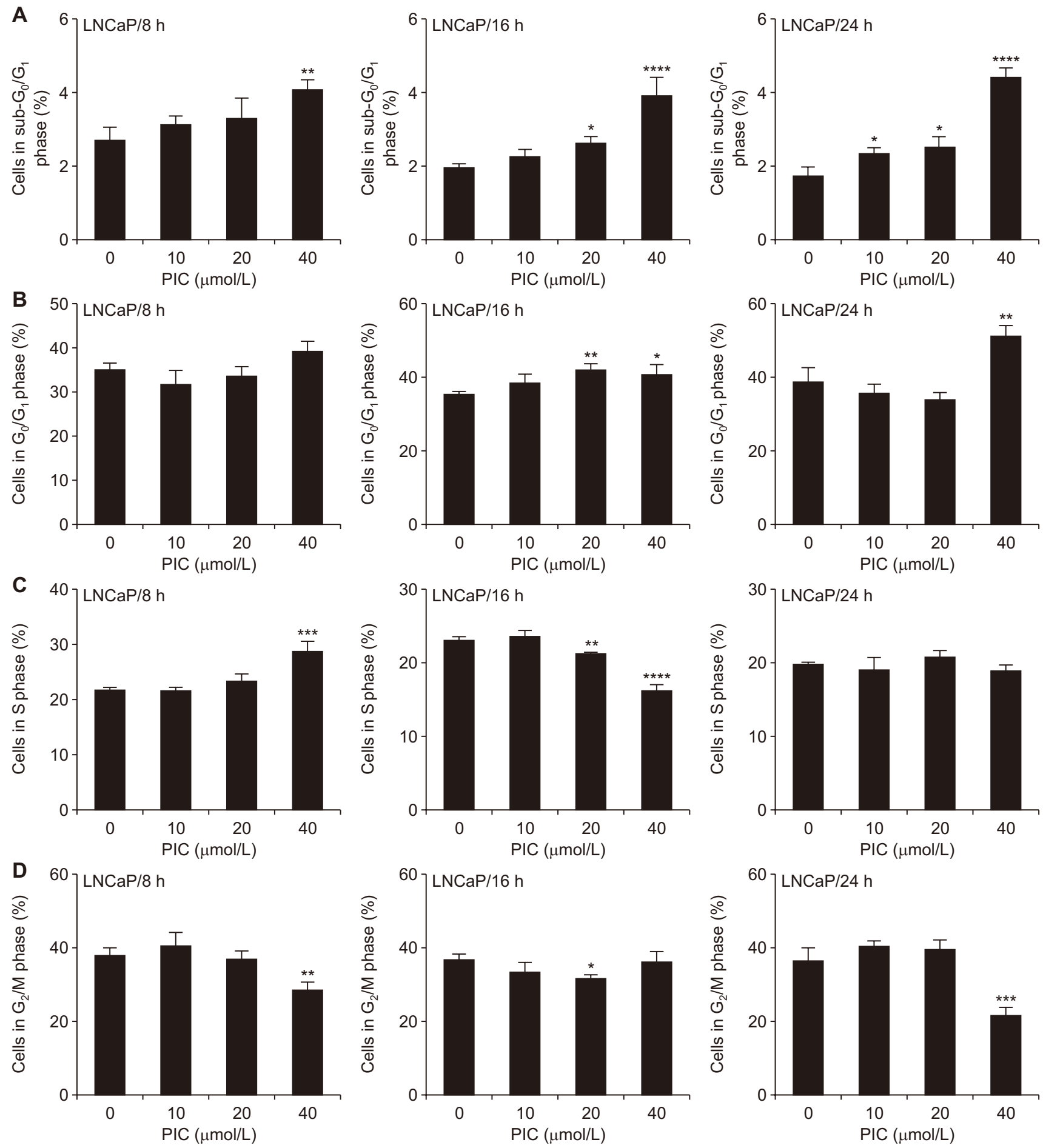

Figure 2. Effect of piceatannol (PIC) on $L N C a P$ cell cycle distribution. Distribution of cells in (A) sub-G $G_{0} / G_{1}$ phase, (B) $G_{0} / G_{1}$ phase, (C) $S$ phase, and (D) $G_{2} / M$ phase of LNCaP cells after treatment with dimethyl sulfoxide (DMSO) or indicated concentrations of PIC for 8,16 , and 24 hours was quantificated by flow cytometry. The results are expressed as mean $\pm \mathrm{SD}(\mathrm{n}=3)$. Significantly different $\left({ }^{*} P<0.05 ;{ }^{* *} P<0.01 ;{ }^{* * *} P<0.001 ;{ }^{* * * *} P<\right.$ 0.0001 ) compared with corresponding DMSO-treated control by one-way analysis of variance followed by Dunnnett's test. The experiments were repeated at least twice with consistent results. Representative data from one such experiment is shown.

control siRNA or p53-siRNA transfected cells (Fig. 5D). Secondly, unlike $L N C a P$ cells, the proportion of sub- $G_{0} / G_{1}$ cells was reduced after PIC treatment in 153 knockdown cells in comparison with control siRNA transfected cells (Fig. 5D). 

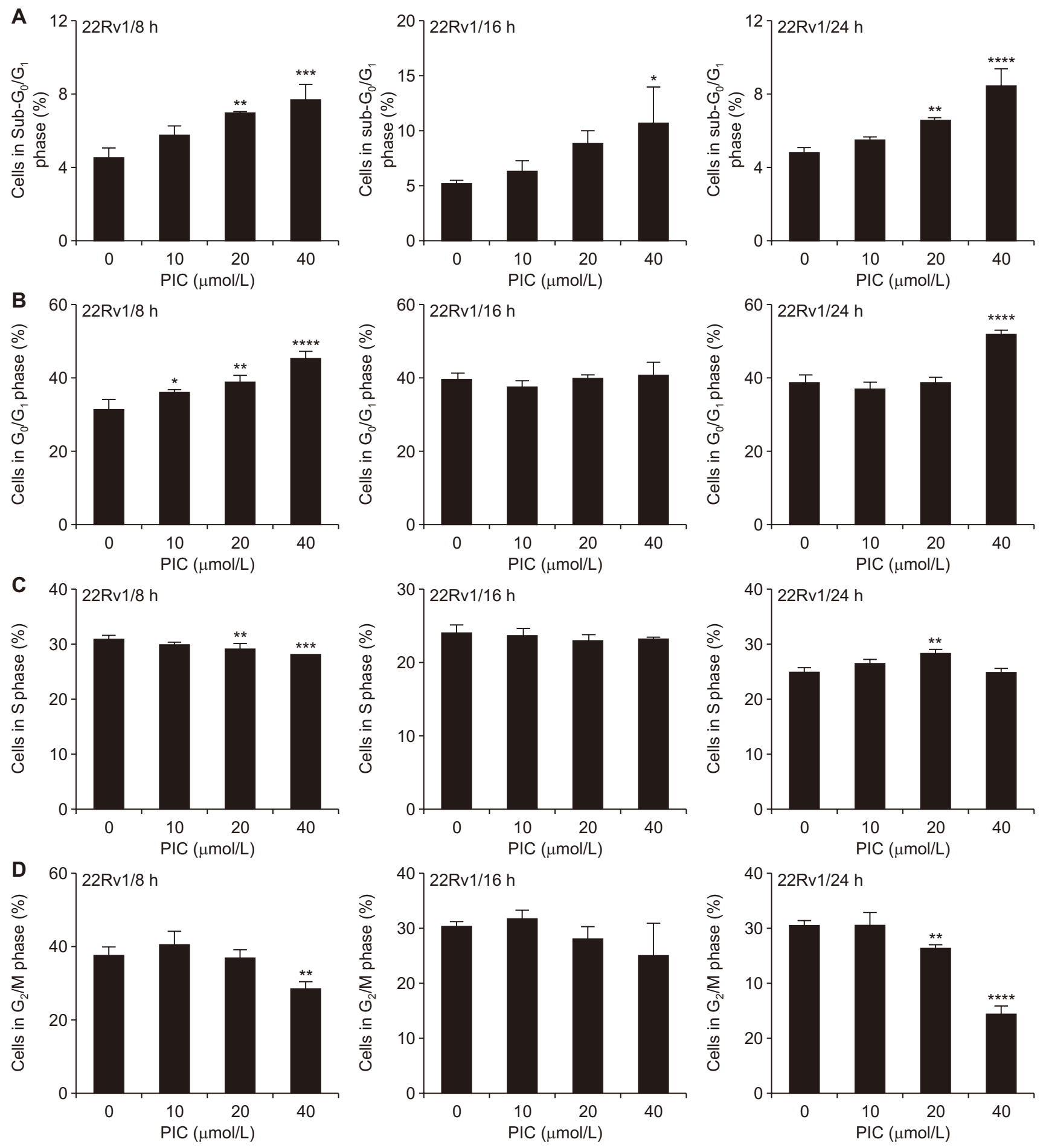

Figure 3. Effect of piceatannol (PIC) on 22Rv1 cell cycle distribution. Distribution of cells in (A) sub- $\mathrm{G}_{0} / \mathrm{G}_{1}$ phase, (B) $\mathrm{G}_{0} / \mathrm{G}_{1}$ phase, (C) $S$ phase, and (D) $G_{2} / M$ phase of $22 R v 1$ cells after treatment with dimethyl sulfoxide (DMSO) or different concentrations of PIC for 8,16 , and 24 hours was quantificated by flow cytometry. The results are expressed as mean $\pm \mathrm{SD}(\mathrm{n}=3)$. Significantly different $\left({ }^{\star} P<0.05 ;{ }^{* \star} P<0.01 ;{ }^{* * *} P<0.001 ;{ }^{* \star * *} P<\right.$ 0.0001 ) compared with corresponding DMSO-treated control by one-way analysis of variance followed by Dunnnett's test. The experiments were repeated twice with consistent results. Representative data from one such experiment is shown.

PFE as a potential source of PIC delayed PCa progression in TRAMP mice

Based on the results obtained from cell experiments, we decided to investigate if the PFE containing relatively large amounts of PIC could affect the lesion progression in TRAMP mice. Epithelial atrophy and decreased acinar mucosa fold- 
A

LNCaP

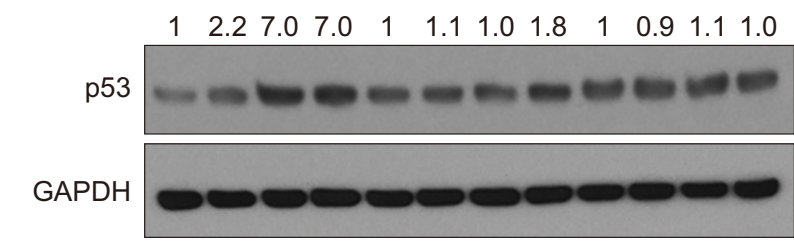

$\begin{array}{llllllllllll}1 & 0.1 & 2.6 & 0.1 & 1 & 1.4 & 2.3 & 13 & 1 & 36 & 20 & 97\end{array}$

p21

$\beta$-actin
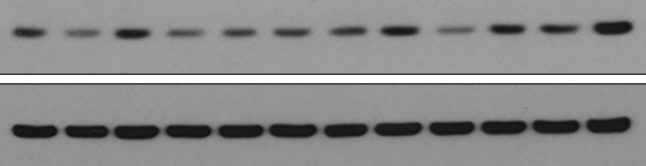

$\begin{array}{llllllllllll}1 & 0.2 & 0.1 & 0.1 & 1 & 0.9 & 0.1 & 0.2 & 1 & 0.8 & 0.2 & 0.1\end{array}$

Cdk4

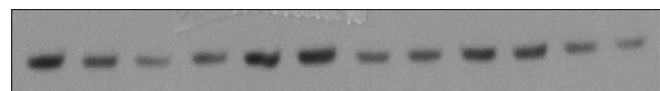

$\begin{array}{lllllllllllll}1 & 0.8 & 0.4 & 0.4 & 1 & 1.7 & 1.7 & 1.3 & 1 & 1.1 & 0.7 & 0.5\end{array}$

Cyclin D1

$=$

GAPDH

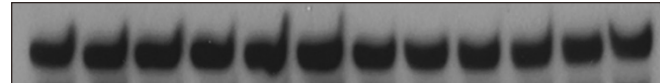

$\mathrm{PIC}(\mu \mathrm{mol} / \mathrm{L}) \frac{0102040}{8 \mathrm{~h}} \frac{0102040}{16 \mathrm{~h}} \frac{0102040}{24 \mathrm{~h}}$
B

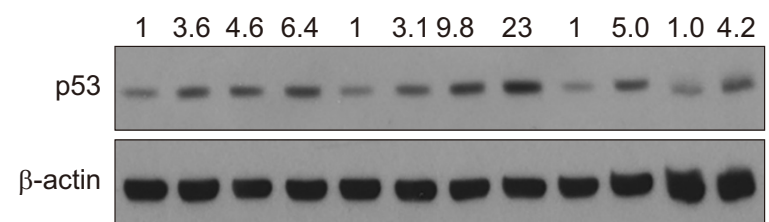

$\begin{array}{llllllllllll}1 & 2.7 & 0.8 & 2.0 & 1 & 1.0 & 1.0 & 1.9 & 1 & 0.8 & 4.0 & 3.4\end{array}$

p21

$\beta$-actin

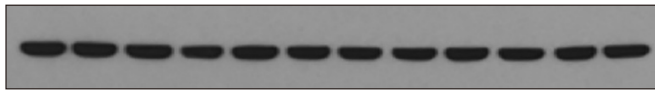

$\begin{array}{llllllllllll}1 & 0.3 & 0.6 & 0.1 & 1 & 0.7 & 0.4 & 0.3 & 1 & 0.8 & 0.3 & 0.1\end{array}$

Cdk4

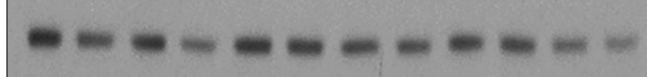

$\beta$-actin

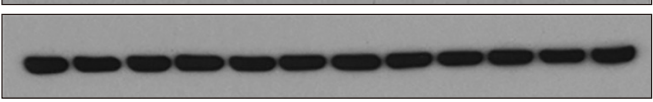

$\begin{array}{llllllllllll}1 & 0.5 & 0.5 & 0.1 & 1 & 0.6 & 0.3 & 0.3 & 1 & 1.2 & 0.8 & 1.1\end{array}$

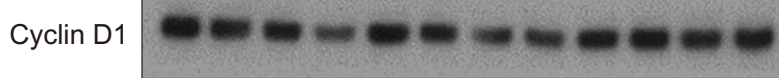

$\beta$-actin

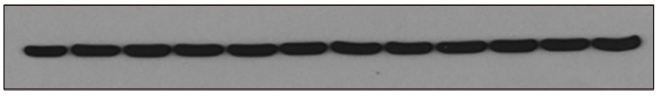

$\mathrm{PIC}(\mu \mathrm{mol} / \mathrm{L})$

Figure 4. Effect of piceatannol (PIC) on the expression of cell cycle-related proteins. Representative immunoblots showing the effect of PIC treatment on (A) LNCaP and (B) 22Rv1 cells. Lysates from both cell lines treated with dimethyl sulfoxide (DMSO) or indicated doses of PIC for 8, 16, and 24 hours were submitted to Western blotting for p53, p21, cyclin-dependent kinase 4 (cdk4), cyclin D1, glyceraldehyde 3-phosphate dehydrogenase (GAPDH), and $\beta$-actin. The numbers on top of the band indicate fold change in protein level compared to corresponding DMSOtreated control. Housekeeping proteins were used for normalization ( $\beta$-actin or GAPDH). The experiments were repeated at least twice with consistent results.

ing were observed in the ventral prostate from TRAMP mice treated for 4 weeks with PFE (Fig. 6A; A5 \& A6). Although recovery of morphology was evident in the PFE-4 wk group, the incidence of uninjured tissue and PIN showed no significant difference compared to their respective CT (Fig. 6B). It is noteworthy that administration of PFE for 4 weeks significantly decreased foci of WDA, which is defined as the first stage of PCa in the TRAMP model (Fig. 6B). The ventral prostate of animals treated for 10 weeks with PFE indicated the progression of proliferative lesions in the TRAMP mice (Fig. 6A; A7 \& A8). There was a significant increase in epithelial tissue classified as normal in the PFE-10 wk group when compared to its respective $\mathrm{CT}$ (Fig. $6 \mathrm{~B}$ ). In addition, the mean percentage of uninjured tissue area was similar to that found in the PFE10 wk group (Fig. 6B). There was no statistically significant difference in the incidence of LGPIN when compared to the control. However, the longer exposure to PFE caused a significant decrease in more aggressive lesions such as HGPIN and WDA (Fig. 6B).

The Western blotting results shown in Figure $6 \mathrm{C}$ demonstrate that PFE was able to alter the expression of important cell cycle regulatory proteins in PCa. The protein level of the cdk4 and cyclin D1 was reduced by PFE after 4 weeks of treatment and the effect was sustained after 10 weeks only for cyclin D1. Both treatments caused an increase in the p21 level (Fig. 6C).

\section{DISCUSSION}

It has been reported that PIC, like resveratrol, has similar anti-cancer properties $[24,36]$. It is known that blocking cancer mechanisms by drugs or factors from food and natural resources may prolong the life span [25]. According to the literature, the mechanism underlying anticarcinogenic action of PIC is related to its cell-cycle arresting, pro-apoptotic, anti-inflammatory, anti-angiogenic, and anti-metastatic properties [26]. The present study demonstrates the PIC's ability to delay the cell cycle progression and inhibit proliferation in selected PCa cells. On the other hand, glycolytic metabolism may not be a target of PIC. Of note, the LNCaP cell line was more sensitive to PIC exposure compared with 22Rv1 cells, which can be probably due to the differences between their genetic background. Another interesting observation of the present study is that PIC increases the p53 expression in 
A

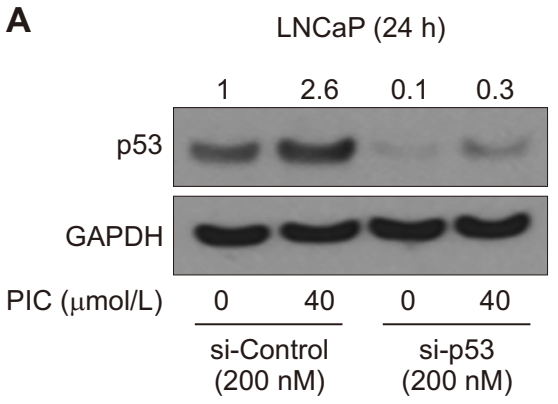

C

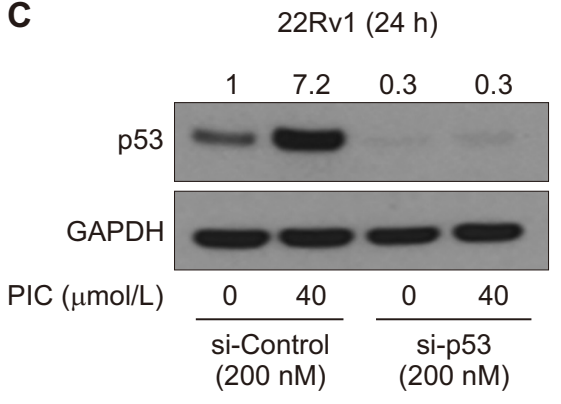

B

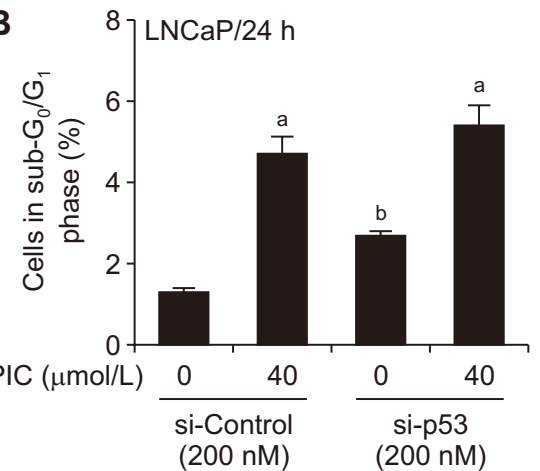

D

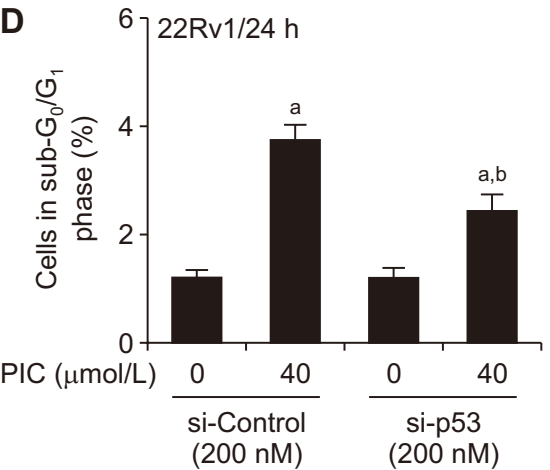

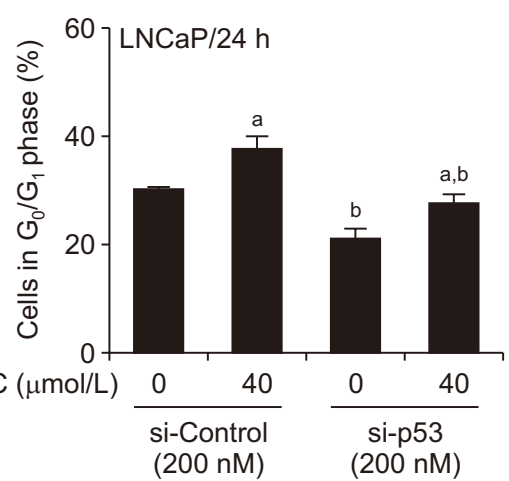

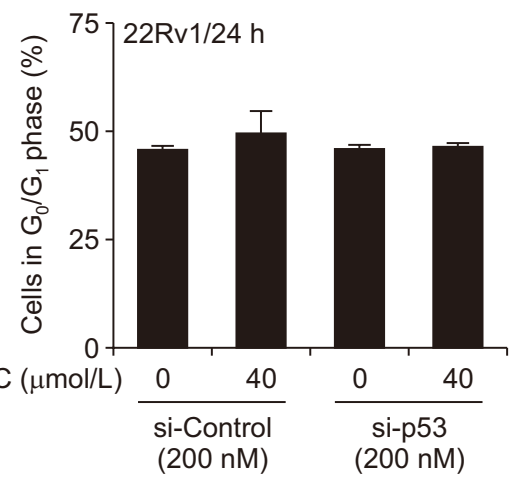

Figure 5. The effect of p53 knockdown on cell cycle in LNCaP and 22Rv1 cells. (A) Immunoblotting for p53 and glyceraldehyde 3-phosphate dehydrogenase (GAPDH) using lysates from LNCaP cells transfected with control siRNA or p53-targeted siRNA and treated with dimethyl sulfoxide (DMSO) or $40 \mu \mathrm{M}$ piceatannol (PIC) for 24 hours. The numbers on top of the band indicate fold change in the protein level compared to control siRNA-transfected cells treated with DMSO. GAPDH was used for normalization. The experiments were repeated twice with consistent results. Representative data from one such experiment is shown. (B) Quantification of cell distribution of LNCaP cells transfected with control siRNA or p53-

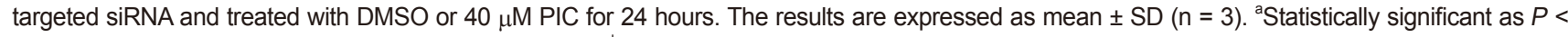
0.05 compared with DMSO-treated control within group; 'Statistically significant as $P<0.05$ compared with the same treatment between groups by one-way analysis of variance followed by Bonferroni's multiple test. The experiments were repeated twice with consistent results. Representative data from one such experiment is shown. (C) Immunoblotting for p53 and GAPDH using lysates from 22Rv1 cells transfected with control siRNA or p53targeted siRNA and treated with DMSO or $40 \mu \mathrm{M}$ PIC for 24 hours. The numbers on top of the band indicate fold change in protein level compared to control siRNA-transfected cells treated with DMSO. GAPDH was used for normalization. The experiments were repeated twice with consistent results. Representative data from one such experiment is shown. (D) Quantification of cell distribution of 22Rv1 cells transfected with control siRNA or p53-targeted siRNA and treated with DMSO or $40 \mu \mathrm{M}$ PIC for 24 hours. The results are expressed as mean \pm SD $(n=3)$. Representative data from one such experiment is shown.

LNCaP cells, which results in cell cycle arrest. However, in $22 R v 1$ cells which harbor mutant $p 53$, the p53 knockdown in the presence PIC provoked no significant effects, such as those seen in LNCaP cells.

The health improvement, protection against damages caused by age-related diseases and their relationship to the consumption of diets rich in polyphenols have been extensively debated over the last decades. In general, the effects achieved with healthy food consumption are enhanced because the biocompounds act in synergy with other substances. Therefore, it is essential to understand how these biocompounds act in the organism and identify elements that can prevent or treat diseases such as cancer. PCa is especially important as a target for chemoprevention from natural products because the tumor development is slow and occurs mainly in elderly men.

The effects of PIC on PCa development and progression are restricted to a few publications. In one study, the activity of PIC was stronger than resveratrol for inhibition of 22Rv1 cell proliferation $\left(\mathrm{IC}_{50} 13.88 \mu \mathrm{mol} / \mathrm{L}\right)$ after 24 hours of treatment [37]. Among all PCa cell lines evaluated in the present study, 22Rv1 cells were least sensitive to PIC exposure. The castration-resistant condition is the most aggressive stage of $\mathrm{PCa}$, and $22 \mathrm{Rv} 1$ cells reflect this feature because they harbor splice variants of androgen receptor lacking the ligand-binding domain [38]. Regarding LNCaP, Lundqvist et al. [39] showed that 48 hours of PIC exposure did not alter cell viability even at higher concentrations $(50 \mu \mathrm{mol} / \mathrm{L})$. However, other studies showed that growth of LNCaP, PC-3, and DU145 cells was significantly affected by PIC treatment, but not in normal prostate epithelial cells $[28,35]$. Although literature data about PIC effects on cell viability are conflicting regarding time of exposure, dose, and cell response, it is a fact that PIC treatment affected PCa cell growth to different 
A

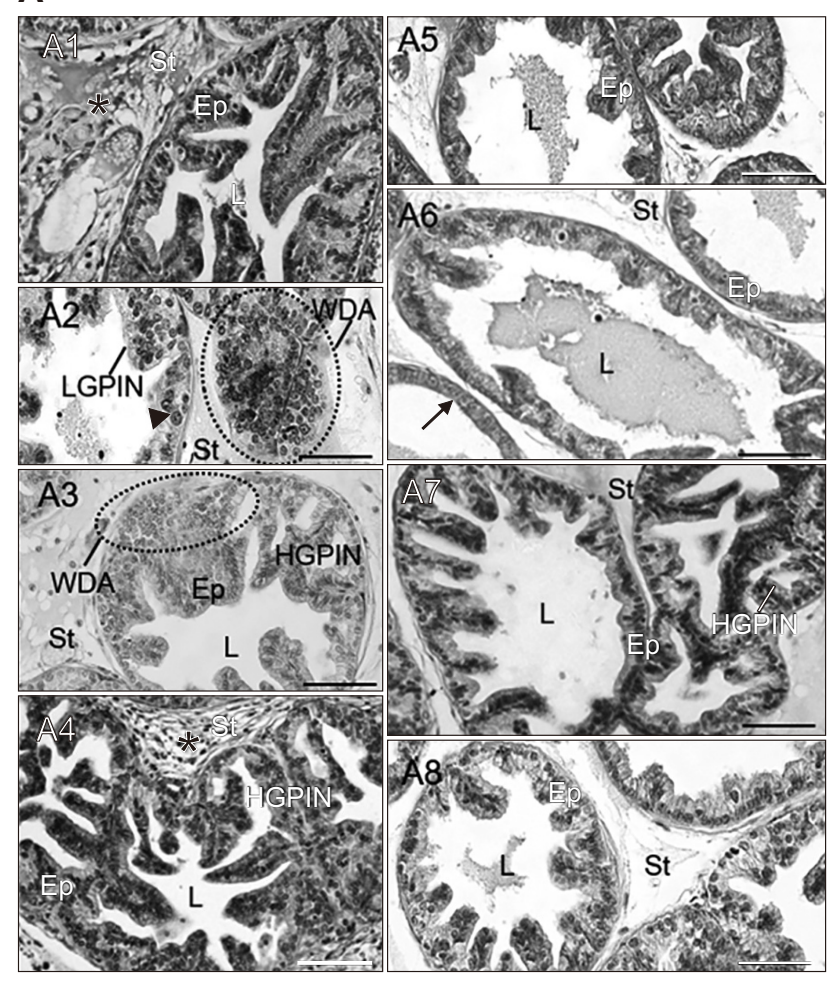

C

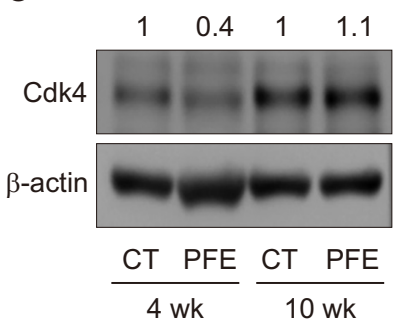

B
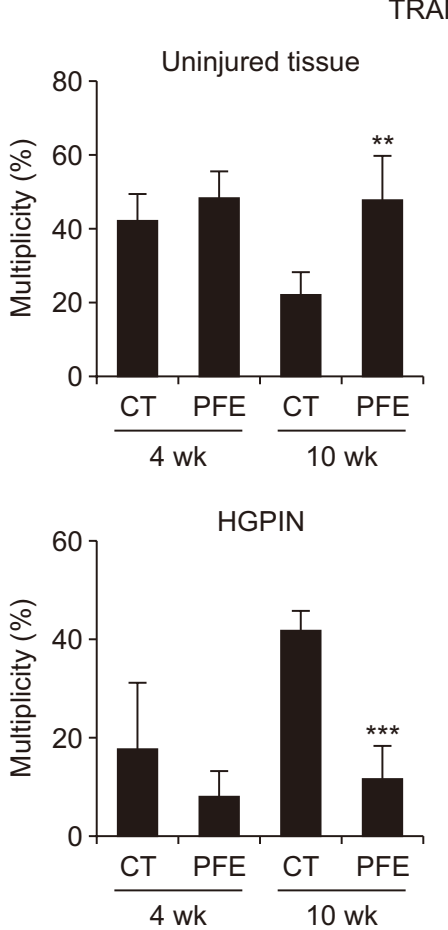
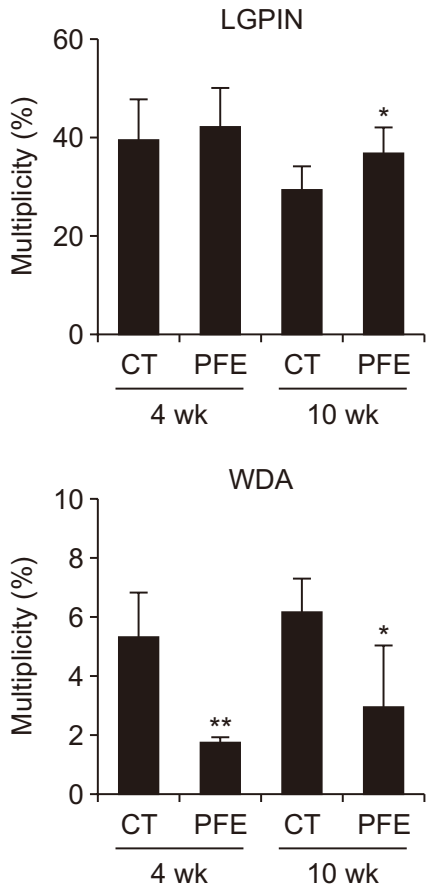

Figure 6. Effects of passion fruit extract (PFE) administration on neoplastic progression and cell cycle proteins modulation in the ventral prostate of Transgenic Adenocarcinoma of the Mouse Prostate (TRAMP) mice. (A) Representative histopathological images from TRAMP mice orally gavaged with water or PFE as described in the Materials and Methods section. Control group (CT) per 4 weeks of treatment (A1-A2): Hyperplastic secretory epithelium (Ep) (low-grade prostatic intraepithelial neoplasia, LGPIN) with folding mucosa and presence of inflammatory cells in the prostatic stroma $(\mathrm{St})\left(^{*}\right)$. A2: Highlight for LGPIN represented by more than one layer of overlapping epithelial cells presenting abundant and pale cytoplasm and prominent nuclei (arrowhead). A3: well-differentiated adenocarcinoma (WDA) (discontinuous circle) represented by the proliferation of epithelial cells towards the stromal compartment and rupture of the basement membrane. CT per 10 weeks of treatment (A3-A4): Abundant presence of pre-neoplastic lesions (high-grade prostatic intraepithelial neoplasia, HGPIN) described by the cribriform and papillary arrangement of hyperplastic epithelial cells within the acinar lumen (L). Increased fibrillar elements in prostatic St (A4) and presence of inflammatory cells $\left({ }^{*}\right)$. Passion fruit extract per 4 weeks of treatment (A5-A6): Simple secretory Ep ranging from cubic to columnar with atrophic regions (arrow). Highlight for reduction of hyperplastic epithelial cells. Passion fruit extract per 10 weeks of treatment (A7-A8): Glandular acini composed of columnar simple Ep with nuclei in the basal position. Some remnants of LGPIN and HGPIN type lesions are noted. Prostatic St with regular appearance (H\&E, $\times 400$, scale bar: $50 \mu \mathrm{m})$. (B) Relative frequency of different morphological features found in the ventral prostate of TRAMP mice ( $n=5$ per group). The results are expressed as mean \pm SD. Significantly different $\left({ }^{*} P<0.05\right.$; $\left.{ }^{* *} P<0.01 ;{ }^{* *} P<0.001\right)$. (C) Representative immunoblots from all experimental groups. Ventral prostate lysates $(n=5)$ from all experimental groups were submitted to Western blotting for cyclin-dependent kinase 4 (cdk4), cyclin D1, p21, and $\beta$-actin. The numbers on top of the band indicate fold change in protein level compared to corresponding water-treated control TRAMP mice. $\beta$-actin was used for normalization.

degrees, independent of hormonal reliance and cell culture conditions. It is important to mention that stilbenes, like resveratrol and PIC, have anti-androgenic activity [39-42], which can directly influence cell survival of hormone-responsive and non-responsive cell lines.

$\mathrm{PIC}$ has been shown to inhibit the cell cycle progression in several different cancer cells by down-regulating cyclins and cdks, and up-regulating p21 and p53 [25,34,43,44]. In DU145 
cells, PIC treatment led to an increase in the percentage of cells in the G1 phase with concomitant down-regulation of cyclin A, cyclin D1, cdk2, and cdk4, as well as decreased cdk2 and cdk4 activity [34]. Hsieh et al. [35] observed a differential cell cycle effect after PIC exposure in LNCaP and PC-3 cells. Unlike our data, LNCaP cells showed an increase in cyclin D1 levels after exposure to 10 and $25 \mu \mathrm{mol} / \mathrm{L}$ of PIC [35]. In the present study, we suggest a differential role of PIC in the cell cycle of LNCaP and 22Rv1 cells. Our results from Western blot analysis did not highlight a differential result in regulatory proteins that would be well distinguished in both cell lines but confirmed the data already seen in the literature. Interestingly, there was no arrest on 22Rv1 cell cycle after p53 siRNA transfection, but there was just an increase of cells in sub- $\mathrm{G}_{0} /$ $\mathrm{G}_{1}$ which could be a result of siRNA transfection. Conversely, LNCaP cell cycle was not only arrested, but p53 levels were increased upon PIC exposure even after the p53 knockdown. In other words, the molecular interaction of PIC with LNCaP cells can lose its efficacy if p53 is down-regulated. It was reported that the overexpression of wild-type p53 attenuates the androgen function, whereas p53 expression at physiological levels stabilizes androgen receptor signaling [45]. According to this study, there is a balance between androgen receptor and p53 expression during the androgen-dependent PCa development, which is abolished during further progression of the disease [45]. The p53 and androgen receptor status is different between LNCaP and 22Rv1 cells. 22Rv1 cells expresses mutant p53 while LNCaP cells have wild-type p53. We propose that the differential effects of PIC seen on 22Rv1 versus LNCaP cells could be due to their different p53 and androgen receptor status.

Another objective of the present study was to investigate if an extract from passion fruit seeds and remaining pulp rich in PIC could affect lesion development in TRAMP mice. TRAMP is a well-established animal model to study PCa progression because it displays similarities to human $\mathrm{PCa}$ in a short period of time [33]. Similar to PIC, our results showed that PFE also contributed to cell cycle delay and, consequently delayed progression of PCa restraining the formation of pre-neoplastic lesions and WDA. One of the genetic characteristics of the TRAMP model is the inactivation of p53 responsible for cell cycle arrest that prevents further progression upon DNA damage $[46,47]$. The present results show that PFE is able to alter the signaling mediated cell cycle regulatory proteins in a manner similar to that PIC exerts in PCa cells.

In summary, the results obtained in the present study indicates that PIC is a regulator of PCa cell growth and its main mechanism is the modulation of cell cycle regulatory proteins. In vivo experiments showed that PFE rich in PIC also retarded PCa progression by altering levels of cell cycle proteins.

\section{ACKNOWLEDGMENTS}

This work was supported by São Paulo State Research
Foundation (FAPESP) (2015/50333-1; 2018/11069-5; 2015/13320-9; 2017/01473-3; 2018/09793-7) and in part by the Coordenação de Aperfeiçoamento de Pessoal de Nível Superior (Brazilian Federal Agency for Support and Evaluation of Graduate Education) Finance Code 001; CNPq (403328/2016-0; 301496/2019-6).

\section{CONFLICTS OF INTEREST}

No potential conflicts of interest were disclosed.

A scholarship from the São Paulo State Research Foundation paid the stipend, health insurance and flight tickets for a University of Pittsburgh-affiliated visiting scholar (Larissa Akemi Kido) from the University of Campinas, Brazil to work in Shivendra Singh's laboratory from September 17, 2018 through March 17, 2019. No financial support was provided to Dr. Singh by São Paulo State Research Foundation. No financial support was provided by Dr. Singh to this visiting scholar, nor did the visiting scholar work on any $\mathrm{NIH}$-funded projects related to Dr. Singh's past, current, or pending support. However, reagents purchased from R01 CA101753 and/or R01 CA225716 were used in some experiments. This study used the Flow Cytometry Facility partly supported by the National Cancer Institute grant P30 CA047904.

\section{SUPPLEMENTARY MATERIALS}

Supplementary materials can be found via https://doi. org/10.15430/JCP.2020.25.2.87.

\section{ORCID}

Larissa Akemi Kido, https://orcid.org/0000-0002-3653-8035

Eun-Ryeong Hahm, https://orcid.org/0000-0002-3197-4575

Su-Hyeong Kim, https://orcid.org/0000-0003-2071-613X

Andressa Mara Baseggio, https://orcid.org/0000-0003-0242-0845

Valeria Helena Alves Cagnon, https://orcid.org/0000-0001-5331-7376

Shivendra V. Singh, https://orcid.org/0000-0002-3733-144X

Mário Roberto Maróstica Jr., https://orcid.org/0000-0001-8877-3160

\section{REFERENCES}

1. Siegel RL, Miller KD, Jemal A. Cancer statistics, 2020. CA Cancer J Clin 2020;70:7-30.

2. Hayashi T, Fujita K, Nojima S, Hayashi Y, Nakano K, Ishizuya $\mathrm{Y}$, et al. High-fat diet-induced inflammation accelerates prostate cancer growth via IL6 signaling. Clin Cancer Res 2018;24:4309- 
Kido et al.

18.

3. Donaldson MS. Nutrition and cancer: a review of the evidence for an anti-cancer diet. Nutr J 2004;3:19.

4. Labbé DP, Zadra G, Yang M, Reyes JM, Lin CY, Cacciatore S, et al. High-fat diet fuels prostate cancer progression by rewiring the metabolome and amplifying the MYC program. Nat Commun 2019;10:4358.

5. Bianchini F, Kaaks R, Vainio H. Overweight, obesity, and cancer risk. Lancet Oncol 2002;3:565-74.

6. Adhami VM, Mukhtar H. Human cancer chemoprevention: hurdles and challenges. Top Curr Chem 2013;329:203-20.

7. Kelloff GJ, Boone CW, Crowell JA, Steele VE, Lubet R, Sigman CC. Chemopreventive drug development: perspectives and progress. Cancer Epidemiol Biomarkers Prev 1994;3:85-98.

8. Khan GN, Gorin MA, Rosenthal D, Pan Q, Bao LW, Wu ZF, et al. Pomegranate fruit extract impairs invasion and motility in human breast cancer. Integr Cancer Ther 2009;8:242-53.

9. Khan SA. The role of pomegranate (Punica granatum L.) in colon cancer. Pak J Pharm Sci 2009;22:346-8.

10. Santillo VM, Lowe FC. Role of vitamins, minerals and supplements in the prevention and management of prostate cancer. Int Braz J Urol 2006;32:3-14.

11. Adhami VM, Khan N, Mukhtar H. Cancer chemoprevention by pomegranate: laboratory and clinical evidence. Nutr Cancer 2009;61:811-5.

12. Mukhtar H, Ahmad N. Green tea in chemoprevention of cancer. Toxicol Sci 1999;52(2 Suppl):111-7.

13. Surh YJ. Cancer chemoprevention with dietary phytochemicals. Nat Rev Cancer 2003;3:768-80.

14. Lall RK, Syed DN, Adhami VM, Khan MI, Mukhtar H. Dietary polyphenols in prevention and treatment of prostate cancer. Int $\mathrm{J}$ Mol Sci 2015;16:3350-76.

15. Cazarin CB, da Silva JK, Colomeu TC, Batista AG, Vilella CA, Ferreira AL, et al. Passiflora edulis peel intake and ulcerative colitis: approaches for prevention and treatment. Exp Biol Med (Maywood) 2014;239:542-51.

16. Pires MM, Gomes AS, Midlej MMBC, São José AR, Rosado PL, Passos HDB. Caracterização do mercado de maracujá. In: Pires MM, São José AR, da Conceição AO, eds. Maracujá: Avanços Tecnológicos e Sustentabilidade. Ilhéus, Editus, pp 21-68, 2011.

17. Martínez R, Torres P, Meneses MA, Figueroa JG, Pérez-Álvarez JA, Viuda-Martos M. Chemical, technological and in vitro antioxidant properties of mango, guava, pineapple and passion fruit dietary fibre concentrate. Food Chem 2012;135:1520-6.

18. Coleta M, Batista MT, Campos MG, Carvalho R, Cotrim MD, Lima TC, et al. Neuropharmacological evaluation of the putative anxiolytic effects of Passiflora edulis Sims, its sub-fractions and flavonoid constituents. Phytother Res 2006;20:1067-73.

19. Barbosa PR, Valvassori SS, Bordignon CL Jr, Kappel VD, Martins MR, Gavioli EC, et al. The aqueous extracts of Passiflora alata and Passiflora edulis reduce anxiety-related behaviors without affecting memory process in rats. J Med Food 2008;11: 282-8.

20. Montanher AB, Zucolotto SM, Schenkel EP, Fröde TS. Evi- dence of anti-inflammatory effects of Passiflora edulis in an inflammation model. J Ethnopharmacol 2007;109:281-8.

21. Zeraik ML, Yariwake JH, Wauters JN, Tits M, Angenot L. Analysis of passion fruit rinds (Passiflora edulis): isoorientin quantification by HPTLC and evaluation of antioxidant (radical scavenging) capacity. Quim Nova 2012;35:541-5.

22. Matsui Y, Sugiyama K, Kamei M, Takahashi T, Suzuki T, Katagata $Y$, et al. Extract of passion fruit (Passiflora edulis) seed containing high amounts of piceatannol inhibits melanogenesis and promotes collagen synthesis. J Agric Food Chem 2010;58:11112-8.

23. Sano $S$, Sugiyama $K$, Ito $T$, Katano $Y$, Ishihata A. Identification of the strong vasorelaxing substance scirpusin $\mathrm{B}$, a dimer of piceatannol, from passion fruit (Passiflora edulis) seeds. J Agric Food Chem 2011;59:6209-13.

24. Piotrowska H, Kucinska M, Murias M. Biological activity of piceatannol: leaving the shadow of resveratrol. Mutat Res 2012; 750:60-82.

25. Kita Y, Miura Y, Yagasaki K. Antiproliferative and anti-invasive effect of piceatannol, a polyphenol present in grapes and wine, against hepatoma AH109A cells. J Biomed Biotechnol 2012; 2012:672416.

26. Surh YJ, Na HK. Therapeutic potential and molecular targets of piceatannol in chronic diseases. Adv Exp Med Biol 2016;928: 185-211.

27. Kwon GT, Jung JI, Song HR, Woo EY, Jun JG, Kim JK, et al. Piceatannol inhibits migration and invasion of prostate cancer cells: possible mediation by decreased interleukin- 6 signaling. J Nutr Biochem 2012;23:228-38.

28. Kim EJ, Park H, Park SY, Jun JG, Park JH. The grape component piceatannol induces apoptosis in DU145 human prostate cancer cells via the activation of extrinsic and intrinsic pathways. J Med Food 2009;12:943-51.

29. Ishihata A, Maruki-Uchida H, Gotoh N, Kanno S, Aso Y, Togashi $S$, et al. Vascular- and hepato-protective effects of passion fruit seed extract containing piceatannol in chronic high-fat diet-fed rats. Food Funct 2016;7:4075-81.

30. Viganó J, Aguiar AC, Moraes DR, Jara JLP, Eberlin MN, Cazarin $\mathrm{CBB}$, et al. Sequential high pressure extractions applied to recover piceatannol and scirpusin $B$ from passion fruit bagasse. Food Res Int 2016;85:51-8.

31. Song H, Jung JI, Cho HJ, Her S, Kwon SH, Yu R, et al. Inhibition of tumor progression by oral piceatannol in mouse 4T1 mammary cancer is associated with decreased angiogenesis and macrophage infiltration. J Nutr Biochem 2015;26:1368-78.

32. Kido LA, Montico F, Sauce R, Macedo AB, Minatel E, Costa DB, et al. Anti-inflammatory therapies in TRAMP mice: delay in PCa progression. Endocr Relat Cancer 2016;23:235-50.

33. Roy-Burman P, Wu H, Powell WC, Hagenkord J, Cohen MB. Genetically defined mouse models that mimic natural aspects of human prostate cancer development. Endocr Relat Cancer 2004;11:225-54.

34. Lee YM, Lim DY, Cho HJ, Seon MR, Kim JK, Lee BY, et al. Piceatannol, a natural stilbene from grapes, induces $\mathrm{G} 1$ cell cycle arrest in androgen-insensitive DU145 human prostate cancer 
cells via the inhibition of CDK activity. Cancer Lett 2009;285:16673.

35. Hsieh TC, Lin CY, Lin HY, Wu JM. AKT/mTOR as novel targets of polyphenol piceatannol possibly contributing to inhibition of proliferation of cultured prostate cancer cells. ISRN Urol 2012; 2012:272697.

36. Seyed MA, Jantan I, Bukhari SN, Vijayaraghavan K. A comprehensive review on the chemotherapeutic potential of piceatannol for cancer treatment, with mechanistic insights. J Agric Food Chem 2016;64:725-37.

37. Kumar A, Lin SY, Dhar S, Rimando AM, Levenson AS. Stilbenes inhibit androgen receptor expression in 22Rv1 castrate-resistant prostate cancer cells. J Med Act Plant 2014;3:1-8.

38. Tepper CG, Boucher DL, Ryan PE, Ma AH, Xia L, Lee LF, et al. Characterization of a novel androgen receptor mutation in a relapsed CWR22 prostate cancer xenograft and cell line. Cancer Res 2002;62:6606-14.

39. Lundqvist J, Tringali C, Oskarsson A. Resveratrol, piceatannol and analogs inhibit activation of both wild-type and T877A mutant androgen receptor. J Steroid Biochem Mol Biol 2017;174:161-8.

40. Horvath Z, Marihart-Fazekas S, Saiko P, Grusch M, Ozsüy M, Harik $M$, et al. Novel resveratrol derivatives induce apoptosis and cause cell cycle arrest in prostate cancer cell lines. Anticancer Res 2007;27(5A):3459-64.

41. Streicher W, Luedeke M, Azoitei A, Zengerling F, Herweg A,
Genze F, et al. Stilbene induced inhibition of androgen receptor dimerization: implications for AR and ARALBD-signalling in human prostate cancer cells. PLoS One 2014;9:e98566.

42. Chakraborty S, Kumar A, Butt NA, Zhang L, Williams R, Rimando $\mathrm{AM}$, et al. Molecular insight into the differential anti-androgenic activity of resveratrol and its natural analogs: in silico approach to understand biological actions. Mol Biosyst 2016;12:1702-9.

43. Wolter F, Clausnitzer A, Akoglu B, Stein J. Piceatannol, a natural analog of resveratrol, inhibits progression through the $S$ phase of the cell cycle in colorectal cancer cell lines. J Nutr 2002;132:298302.

44. Kuo PL, Hsu YL. The grape and wine constituent piceatannol inhibits proliferation of human bladder cancer cells via blocking cell cycle progression and inducing Fas/membrane bound Fas ligand-mediated apoptotic pathway. Mol Nutr Food Res 2008;52: 408-18.

45. Cronauer MV, Schulz WA, Burchardt T, Ackermann R, Burchardt $M$. Inhibition of p53 function diminishes androgen receptormediated signaling in prostate cancer cell lines. Oncogene 2004; 23:3541-9.

46. Greenberg NM, DeMayo F, Finegold MJ, Medina D, Tilley WD, Aspinall JO, et al. Prostate cancer in a transgenic mouse. Proc Natl Acad Sci USA 1995;92:3439-43.

47. Levine AJ, Momand J, Finlay CA. The p53 tumour suppressor gene. Nature 1991;351:453-6. 